\title{
Editorial
}

\section{The radial approach for coronary angiography and stenting}

Remarkable technological advances have occurred in the field of interventional cardiology - for example, the development of smaller, dependable stent systems that can be delivered through $6 \mathrm{~F}$ guide catheters. As a result, the technique of transradial coronary stenting has evolved under the leadership of Keimeneij and others. Although the procedure has been adopted at numerous centres around the world, many cardiologists continue to question the utility of the procedure.

\section{Benefits}

The superficial location of the radial artery allows easy haemostasis, and access site bleeding complications are virtually eliminated. ${ }^{12}$ Inexpensive mechanical compression devices safely obtain haemostasis, and personnel use is minimised. Patients are ambulatory immediately after the procedure and hospital length of stay is significantly reduced. Compared to the femoral approach, there is substantial economic benefit because of reduced vascular complications and shorter hospital stay. ${ }^{3-5}$

From the patient's perspective, the most important benefit is a substantial reduction in morbidity. Rapid ambulation reduces back pain and the need for bedpans or indwelling bladder catheters. Recent improvements in the technique have decreased the pain of catheter insertion, and the discomfort of catheter removal is less than for the femoral approach. Thus, patients prefer the transradial over the femoral approach. ${ }^{67}$

The left radial artery is an excellent access site for interventions involving left internal mammary artery bypass grafts. The femoral approach for these procedures is sometimes challenging because of extreme tortuosity, poor guide catheter coaxiality and support, and difficulty reaching distal lesions with standard length balloon catheters. Ostial dissection of the internal mammary artery is a potential complication of this situation. ${ }^{8}$ The left radial artery allows a shorter, more direct approach, and improved transradial left internal mammary curve (Boston Scientific, Maple Grove, Minnesotta, USA) creates an easier procedure.

\section{Limitations}

Postprocedure radial artery occlusion occurs in a small percentage of patients. This can be minimised by using higher heparin doses, treatment of the artery with verapamil before sheath insertion, avoiding the use of oversized sheaths in smaller arteries, and minimising postprocedure arterial compression time. However, the procedure should not be performed in patients without an intact palmar arch and a documented dual blood supply to the hand. Seven and $8 \mathrm{~F}$ guide catheters can be used in some patients, but procedures requiring them are probably best performed from the femoral approach. While all patients are not candidates for transradial access, it can be performed in up to $90 \%$ of cases. ${ }^{4}$

The procedure has a definite learning curve and this has been a major impediment to its adoption at many centres. Consistent small artery access and the use of $6 \mathrm{~F}$ guide catheters with unfamiliar curves are techniques that must be learned. However, the ease of use of new low profile stent delivery systems and better $6 \mathrm{~F}$ guides have significantly shortened the learning curve. Numerous transradial meetings and preceptorships are available, as well as computer based learning tools. Information regarding these and other topics is being constantly updated on the Radial Force web site (www.radialforce.com).

\section{Does the radial artery belong to the} interventionalist or the surgeon?

The use of calcium channel blockers to prevent arterial spasm has resulted in the re-emergence of the radial artery as a conduit for coronary bypass grafting. There is concern in the surgical community that the preoperative use of the radial artery for catheterisation could increase the risk of graft thrombosis. Unfortunately, no studies that specifically address this question are currently available.

Interventional procedures are now an important method of coronary revascularisation, and the number of patients undergoing bypass surgery has stopped rising. ${ }^{9}$ In one recent study, only $13 \%$ of patients admitted with unstable coronary syndromes subsequently underwent coronary bypass surgery compared with $52 \%$ being managed with an interventional procedure. ${ }^{4}$

One approach in patients in whom the radial artery might be used surgically would to be perform the diagnostic procedure from the groin. Reasons to use the transradial approach for diagnostic procedures are less compelling than with coronary interventional procedures. Smaller diagnostic catheters and lower heparin doses have reduced femoral complications as well as the need for prolonged bed rest in these patients. Indeed, outpatient femoral coronary arteriography is now a routine procedure. At our hospital, diagnostic radial angiography is generally performed only in patients who are likely to undergo an ad hoc intervention.

\section{Closure devices}

Haemostasis following femoral interventional procedures can also be attained with collagen vascular sealants and percutaneous suture closure devices. ${ }^{10}{ }^{11}$ These allow immediate sheath removal even with full anticoagulation, and many patients are ambulatory within four hours. However, these devices cannot be used in patients with peripheral vascular disease, and vascular complications occur in $2-4 \%$ of patients. ${ }^{12}{ }^{13}$ With the added cost of the closure device, the transradial approach is more economical (Mann et al, unpublished data, 1999).

\section{Summary}

The transradial approach for coronary intervention is associated with primary success rates comparable to the femoral approach and fewer access site bleeding complications. It is particularly useful in patients who are at higher risk for vascular complications, such as unstable patients who have received either thrombolytic or platelet glycoprotein IIb/IIIa inhibitors. The morbidity of the procedure is less, and patients prefer the radial approach. The learning curve now is much shorter with newer stent delivery systems, and interventionalists should strongly consider using this alternative access site.

TIFT MANN

Wake Heart Associates,

3000 New Bern Avenue, G100,

Raleigh, NC 27610, USA 
1 Kiemeneij F, Laarman G. Transradial artery coronary angioplasty. Am Heart F 1995;129:1-8.

2 Mann T, Cubeddu G, Schneider J, et al. Clinical evaluation of current stent deployment strategies. F Invas Cardiol 1996;8(suppl D):30-5.

3 Kiemeneij F, Hofland J, Laarman G, et al. Cost comparison between two modes of Palmaz-Schatz coronary stent implantations: transradial bare stent technique vs. transfemoral sheath-protected stent technique. Cathet Cardiovasc Diagn 1995;35:301-8.

4 Mann, T, Cubeddu G, Bowen J, et al. Stenting in acute coronary syndromes: a comparison of radial versus femoral access sites. $\mathcal{F}$ Am Coll Cardiol 1998; 32:572-6.

5 Mann T, Cubeddu G, Schneider J, et al. Right radial access for PTCA: A prospective study demonstrates reduced complications and hospital charges. F Invas Cardiol 1996;8(suppl D):40-4

6 Kiemeneij F, Laarman GH, Odekerken D, et al. A randomized comparison of percutaneous transluminal coronary angioplasty by the radial, brachial and femoral approaches: the access study. F Am Coll Cardiol 1997;29: 1269-75.
7 Cooper CJ, El-Shiekh RA, Blaesing LD, et al. Patient preference for cardiac catheterization via the transfemoral approach [abstract]. 7 Am Coll Cardiol catheterization via the t
$1997 ; 29$ (suppl A):310A.

8 Devlin G, Schwartz L, Drouin K, et al. The short- and long-term outcome of left internal mammary artery angioplasty. F Invas Cardiol 1997;10:301-5.

9 Detre KM, Rosen A, Bost, JE, et al. Contemporary practice of coronary revascularization in U.S. hospital participating in the bypass angioplasty revascularization investigation. (BARI). f Am Coll Cardiol 1996;28:609-15.

10 deSwart H, Dijkman L, Hofstra L, et al. A new hemostatic puncture closure device for the immediate sealing of arterial puncture sites. Am $\mathcal{F}$ Cardiol 1993;72:445-9.

11 Carere RG, Webb JG, Ahmed T, et al. Initial experience using Prostar: a new device for percutaneous suture mediated closure of arterial puncture sites. Cathet Cardiovasc Diag 1996;37:367-72.

12 Cattelans, N, Gerckens U, Muller R, et al. The Prostar Plus percutaneous closure device versus manual compression following coronary interventions [abstract]. Circulation 1996;94:I-484.

13 Baim D, Pinkerton C, Schatz R, et al. Acute results of the STAND II percutaneous vascular surgical device trial [abstract]. Circulation 1997;96:I-443. 